\title{
USO IRRACIONAL DE ANTIBIÓTICOS, QUAIS OS FATORES ENVOLVIDOS?
}

Livia Bessa dos Santos Costa ${ }^{1}$, Lilian Karoliny Oliveira Lima ${ }^{1}$, Eliene dos Santos da Silva

Costa $^{1}$, Allan Barroso Araújo Grisólia ${ }^{1}$, Daniella Paternostro de Araújo Grisólia ${ }^{1}$

${ }^{1}$ Centro Universitário Fibra

E-mail para correspondência: livi4bessa@gmail.com

Submetido em: 11/06/2021 e aprovado em: 02/08/2021

\section{RESUMO}

Introdução: os antibióticos são medicamentos utilizados no combate de doenças infecciosas de alto risco causadas por bactérias. De acordo com a Organização Mundial da Saúde, o Brasil é o país que mais consome de forma indiscriminada essa classe de medicamento. Objetivos: o trabalho teve por objetivo identificar a partir de uma análise na literatura a causa principal do uso irracional de antibióticos, apontar o principal agravante do uso indevido dessa classe e enfatizar a importância do papel do farmacêutico neste cenário. Métodos: a pesquisa foi realizada a partir de uma revisão integrativa, com busca eletrônica de artigos nas bases de dados BVS, SCIELO, PUBMED, CINHHL, através de descritores: "Uso irracional de antibióticos", "fatores da automedicação de antibióticos", "consequências do uso irracional de antibióticos" e "importância do farmacêutico" no período de 2010 a 2020. Resultados e discussão: com base no levantamento de dados, os principais fatores que levaram a automedicação de antimicrobianos foram o uso de prescrições antigas, alívio rápido de sintomas, dificuldade de acesso ao serviço de saúde pública e conhecimento prévio da patologia. Conclusão: O principal problema relacionado ao uso irracional de antimicrobianos foi a resistência bacteriana e foi possível observar que os autores reconhecem a importância do papel do farmacêutico na promoção da racionalização do uso deste medicamento.

Palavras-chave: Antibiótico, resistência bacteriana, farmacêutico.

\begin{abstract}
Introduction: antibiotics are medicines used to fight high-risk infectious diseases caused by bacteria. According to the World Health Organization, Brazil is the country that most indiscriminately consumes this class of medication. Aims: the aim of this study was to identify, based on an analysis in the literature, the main cause of the irrational use of antibiotics, to point out the main aggravating factor of the misuse of this class and to emphasize the importance of the role of the pharmacist in this scenario. Methods: The research was conducted from an integrative review, with electronic search for articles in the BVS, SCIELO, PUBMED, CINHHL databases, using descriptors: "Irrational use of antibiotics", "factors of antibiotic selfmedication", "consequences of irrational use of antibiotics" and "importance of the pharmacist" in the period 2010 to 2020. Results and discussion: Based on the data survey, the main factors that led to self-medication of antimicrobials were the use of old prescriptions, rapid relief of symptoms, difficulty in accessing public health service and prior knowledge of the pathology. Conclusion: the main problem related to the irrational use of antimicrobials was bacterial resistance and it was also possible to observe that the authors recognize the importance of the role of the pharmacist in promoting the rationalization of the use of this drug.

Keywords: HIV; smartphone; mobile applications; drug interactions; review
\end{abstract}




\section{INTRODUÇÃO}

Os antibióticos representam uma das mais importantes descobertas para a classe médica, que teve seu marco inicial no ano de 1928 com o descobrimento da Penicilina por Alexandre Fleming. Com este achado foi aberta as portas de uma nova era pela Indústria Farmacêutica que passou a produzir a Penicilina e outros antibióticos em massa objetivando combater quadros infecciosos de alto risco ${ }^{(1)}$

Estudos mostram o Brasil como o quarto país que mais faz uso de medicamentos, estimando-se que 40\% destes sejam antibióticos. Esta prática é evidenciada principalmente em decorrência da automedicação, o que ocasiona resistência à diversos microrganismos. Além disso, estes medicamentos constituem um grupo altamente prescritos na atenção primária, ocupando um dos primeiros lugares entre as classes mais utilizadas ${ }^{(2)}$.

Diante disto, é possível observar a ocorrência do uso excessivo desta classe medicamentosa por parte da população, que tem por consequência um desiquilíbrio na relação homem e bactérias, podendo as mesmas apresentar mecanismo de resistência sejam eles extrínseco ou intrínseco ${ }^{(3)}$.

A resistência bacteriana é uma mutação espontânea e recombinações de genes que ocorre em cepas de microrganismo, fazendo com que estas sejam capazes de permanecer se multiplicando na presença de doses elevadas de antibióticos. Essa resistência provoca maiores riscos de complicações nos quadros clínicos, consequentemente elevando as taxas de morbidade, mortalidade, prolongamento de doenças e aumento de custo ${ }^{(4)}$.

Atualmente, a resistência bacteriana representa um problema de saúde pública, onde as infecções provocam mortes no mundo e, principalmente, nos países menos desenvolvidos, representando, desta forma, uma ameaça para humanidade. Muitos são os motivos que favorecem o processo de resistência aos antibióticos utilizados no tratamento de infecções, como o uso irracional a partir da prática da automedicação, o descumprimento da prescrição médica, dúvida de diagnóstico e a falta de programas educativos que promova informações para o uso correto do mesmo ${ }^{(5)}$.

Denomina-se automedicação a prática de utilizar medicamento sem qualquer orientação de um profissional da saúde. Este uso indevido é muito comum entre a população, o que torna esse ato altamente perigoso quando se pensa nos riscos à saúde. As consequências da automedicação vão desde mais leves ao letais, e quando se trata de antimicrobianos esta prática é apontada como um dos principais fatores para o surgimento de bactérias multirresistentes ${ }^{(6)}$. 
Nesse contexto, a Agência Nacional de Vigilância Sanitária (ANVISA) no ano de 2011, visando reduzir os impactos do uso indiscriminado de antimicrobianos publicou a Resolução de Diretoria Colegiado (RDC) No 20/2011, que impõe alguns critérios para dispensação/venda dessa classe de medicamento como por exemplo a obrigatoriedade da apresentação de receita médica em duas vias com validade de $10 \operatorname{dias}^{(7)}$. No entanto, vale ressaltar que apesar de restrições serem impostas, a compra e venda deste medicamento ainda ocorre de forma preocupante.

Mediante ao exposto e com a preocupação referente uso indiscriminado dos antibióticos, este trabalho busca a partir de uma revisão integrativa identificar o principal motivo que leva ao uso inadequado desta classe medicamentosa e pontuar a importância da atenção farmacêutica na promoção do uso racional deste medicamento.

\section{MÉTODOS}

O presente estudo foi realizado a partir de uma revisão integrativa, uma nova abordagem metodológica que é capaz de proporcionar através de estudos experimentais e não experimentais informações mais amplas sobre um determinado problema e/ou assunto, resultando assim em um corpo de conhecimento ${ }^{(8)}$.

O trabalho foi desenvolvido com base na principal pergunta norteadora: "Quais os fatores que favorecem o uso irracional de antibióticos?"; seguido das perguntas secundárias: "Quais as consequências do uso irracional de antibióticos? e "Qual a importância do farmacêutico na promoção do uso racional de antibióticos?"

Para levantamento dos artigos na literatura foram utilizados por meio de busca eletrônica trabalhos científicos nas bases de dados BVS, SCIELO, PUBMED, CINHHL.

A busca por artigos foi realizada pela combinação das seguintes combinações de palavras-chaves de acordo com o assunto em questão: "Uso irracional de antibióticos", "fatores da automedicação de antibióticos", "consequências do uso irracional de antibióticos" e "importância farmacêutico"; sendo inseridas as quatro palavras-chaves em cada base, sem utilização de termos truncados ou operadores booleanos.

Foram estabelecidos para a obtenção dos resultados fatores de inclusão e exclusão para a análise da temática proposta. Os critérios de inclusão, foram: a) Publicação entre o período de 2010 a 2020, b) apenas em língua portuguesa, c) responder os objetivos proposto no trabalho. No que se diz respeito aos critérios de exclusão: e) não foram utilizadas monografia e 
dissertações, f) arquivos que não estavam disponíveis na integra g) artigos repetidos.

Após a realização da busca em cada base de dados, encontrou-se 4.899 artigos no total, e 41 artigos corresponderam aos critérios de inclusão/ exclusão estabelecidos para a pesquisa. Posteriormente, seguiu-se com a análise dos artigos pelo título para análise de duplicata ou ainda relação direta com as questões norteadoras, enquadrando-se apenas 20 artigos com esses quesitos, eles foram numerados de 1 a 20 na sequência que foram encontrados e, prosseguiuse com a extração dos achados que respondessem de modo qualitativo às perguntas norteadoras, não importando a metodologia aplicada no estudo, conforme descrito na Figura 1.

Figura 1: Fluxograma de identificação, seleção e inclusão dos artigos, para o desenvolvimento do estudo.

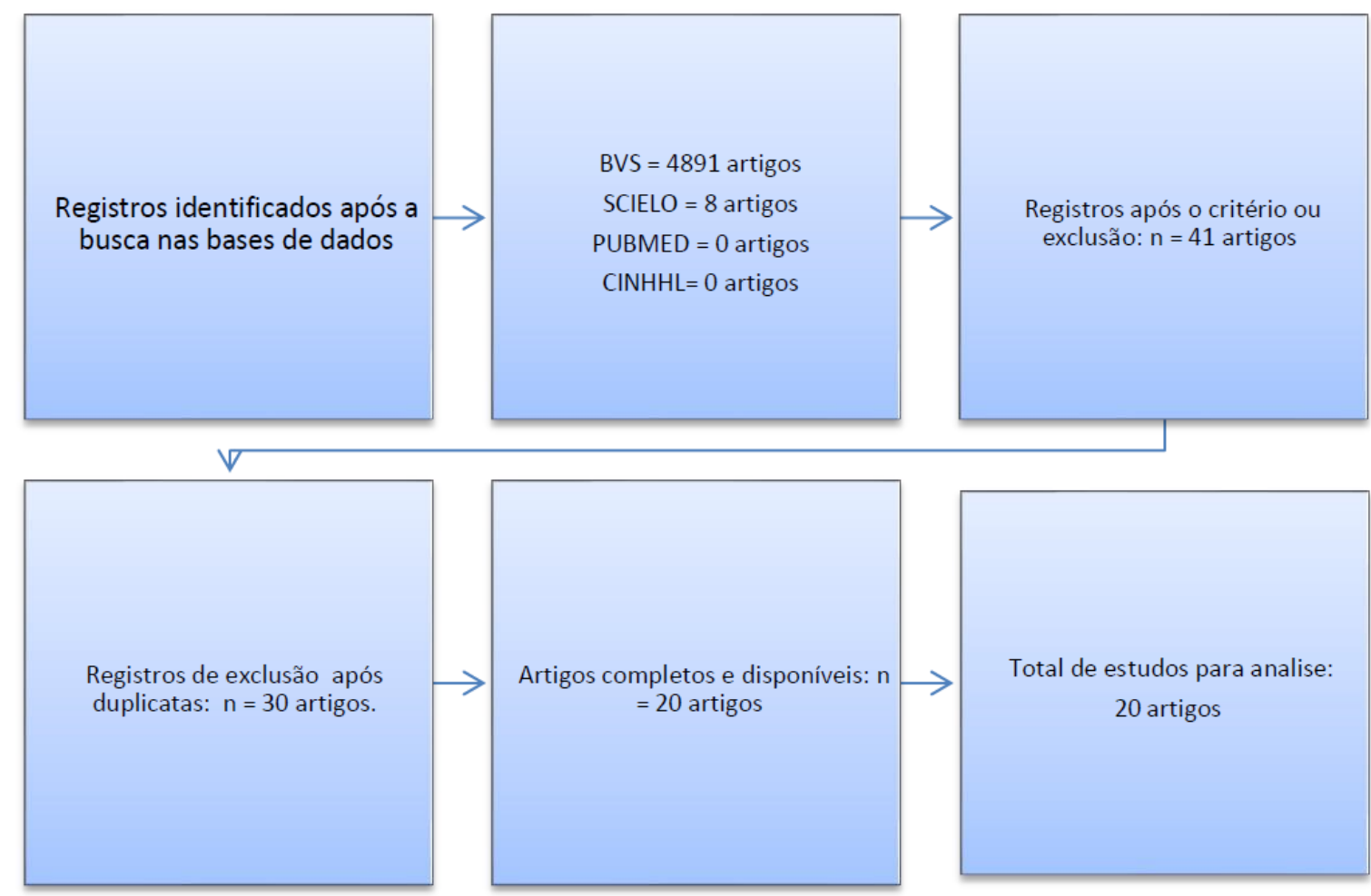

Fonte: Os autores.

\section{RESULTADOS E DISCUSSÃO}

Dentre os 20 artigos analisados, 10 trazem discussões relevantes e atuais frente a temática em questão e apontaram os principais fatores que levaram a realização da automedicação de antimicrobianos por parte da população. Deve-se destacar como justificativa para este feito: Praticidade, alívio rápido de sintomas, uso de prescrições antigas e dificuldade de acesso ao serviço de saúde apresentados no quadro 1. 
Quadro 1: Fatores que levam o paciente se automedicar com antibióticos.

\begin{tabular}{|c|c|c|}
\hline Autores & Ano de publicação & Desfechos \\
\hline ARAÚJO e GALATO & 2012 & $\begin{array}{l}\text { Problemas de saúde simples; Influência de } \\
\text { amigos e/ou familiares; Praticidade. }\end{array}$ \\
\hline DANDOLINI et al & 2012 & Publicidade. \\
\hline SANTOS et al & 2012 & $\begin{array}{l}\text { Alívio rápido de sintomas; Conhecimento } \\
\text { prévio da doença; Prescrições antigas. }\end{array}$ \\
\hline BRAOIOS et al & 2013 & $\begin{array}{l}\text { Consumo de } \\
\text { medicamento sem prescrição }\end{array}$ \\
\hline PINTO, BUENO e VIEIRA & 2012 & $\begin{array}{l}\text { Diagnóstico inespecífico; Demora do } \\
\text { resultado para a definiçãa da } \\
\text { farmacoterapia. }\end{array}$ \\
\hline ALVES e MALAFAIA & 2014 & Uso de prescrições antigas. \\
\hline FRITZEN, COLET e OLIVEIRA & 2014 & $\begin{array}{l}\text { Menos número de consultas; Infecção } \\
\text { urinária durante gestação. }\end{array}$ \\
\hline GAMA e SECOLI & 2017 & $\begin{array}{l}\text { Percepção de que o problema de saúde não } \\
\text { requeria atenção médica; Falta de tempo; } \\
\text { Dificuldade de acesso aos serviços de } \\
\text { saúde. }\end{array}$ \\
\hline LIMA, et al. & 2017 & $\begin{array}{l}\text { Difícil controle de fiscalização na farmácia; } \\
\text { Falta de programas para promoção do uso } \\
\text { racional de antibióticos. }\end{array}$ \\
\hline
\end{tabular}

Fonte: Os autores

No que se diz respeito aos demais objetivos propostos no estudo, foi possível identificar 13 autores que pontuaram as consequências frente ao uso irracional de antimicrobianos (quadro 2) e 6 estudiosos que defenderam a importância do papel do profissional farmacêutico na promoção do uso racional desta classe medicamentosa (quadro 3). Se torna evidente mediante aos achados a preocupação quanto ao surgimento de bactérias multirresistente e ao índice elevado da resistência bacteriana como também a importância do profissional capacitado no ato da dispensação, visando a garantia de uma farmacoterapia de qualidade e segura para o paciente. 
Quadro 2: Achados que apontam as consequências do uso irracional de antibióticos.

\begin{tabular}{|c|c|c|}
\hline Autores & Ano de publicação & Desfechos \\
\hline DOS SANTOS et al & 2010 & Bactérias resistentes em ambiente hospitalar. \\
\hline DANDOLINI et al & 2012 & Intoxicação e morte. \\
\hline ARAÚJO e GALATO & 2012 & $\begin{array}{l}\text { Aumento do tempo de internação hospitalar } \\
\text { e do consumo de medicamentos. }\end{array}$ \\
\hline PINTO, BUENO e VIEIRA & 2013 & $\begin{array}{l}\text { Aumento da resistência bacteriana; } \\
\text { Toxicidade. }\end{array}$ \\
\hline BRAOIOS et al & 2013 & $\begin{array}{l}\text { Mascaramento de certos sintomas; } \\
\text { Resistência bacteriana; Desenvolvimento de } \\
\text { reações adversas. }\end{array}$ \\
\hline ALVES e MALAFAIA & 2014 & Resistência Bacteriana. \\
\hline FRITZEN, COLET e OLIVEIRA & 2014 & Toxicidade fetal e lesões variadas. \\
\hline SILVA e SILVA JÚNIOR & 2015 & $\begin{array}{l}\mathrm{O} \text { uso prolongado e indiscriminado de } \\
\text { antimicrobianos é um dos principais fatores } \\
\text { relacionados ao surgimento de bactérias } \\
\text { multirresistentes. }\end{array}$ \\
\hline GAMA e SECOLI & 2017 & $\begin{array}{l}\text { Resistência bacteriana; Elevado risco de } \\
\text { reações adversas. }\end{array}$ \\
\hline LIMA et al & 2017 & Resistência microbiana na população. \\
\hline LIMA, BENJAMIN e SANTOS & 2017 & $\begin{array}{l}\text { Aumento da resistência bacteriana; Elevando } \\
\text { o custo final para a instituição hospitalar. }\end{array}$ \\
\hline VIEIRA e VIEIRA & 2017 & $\begin{array}{l}\text { Resistência bacteriana; Aumento da } \\
\text { morbidade, mortalidade, prolongamento no } \\
\text { tempo de internação, elevação nos custos do } \\
\text { tratamento; Toxicidade fetal e lesões } \\
\text { variadas. }\end{array}$ \\
\hline CABRAL et al & 2018 & $\begin{array}{l}\text { Longos períodos de internação, custos mais } \\
\text { elevados, maior morbidade e mortalidade } \\
\text { nos hospitais e resistência bacteriana. }\end{array}$ \\
\hline
\end{tabular}


Quadro 3: Achados que ressaltam a importância do farmacêutico na promoção do uso racional de antibióticos.

\begin{tabular}{|c|c|c|}
\hline Autores & Ano de publicação & Desfechos \\
\hline CARNEIRO et al & 2011 & $\begin{array}{l}\text { A importante da intervenção do profissional } \\
\text { farmacêutico na dispensação do medicamento } \\
\text { prescrito à paciente; O farmacêutico apresenta-se } \\
\text { como um profissional que possui uma visão ampla da } \\
\text { realidade da saúde. }\end{array}$ \\
\hline DANDOLINI et al & 2012 & $\begin{array}{l}\text { O farmacêutico exige a prescrição médica para o } \\
\text { antibiótico e explica a importância de usar } \\
\text { corretamente o medicamento, utilizando dentro da } \\
\text { posologia adequada. }\end{array}$ \\
\hline BRAOIOS et al & 2013 & $\begin{array}{l}\text { Ações que orientam a população sobre os riscos } \\
\text { relacionados ao uso de antimicrobianos. }\end{array}$ \\
\hline ALVES e MALAFAIA & 2014 & $\begin{array}{l}\text { A dispensação racional de fármacos precisa ser } \\
\text { estimulada como parte integrante da promoção à } \\
\text { saúde e do bem-estar da população em geral. }\end{array}$ \\
\hline MARTINS et al & 2014 & $\begin{array}{l}\text { Importância de informações adequada sobre } \\
\text { medicamento prescrito especialmente os da classe de } \\
\text { antibióticos; Importância do serviço de dispensação } \\
\text { farmacêutica; Vínculo e diálogo entre paciente e } \\
\text { farmacêutico; Avaliação de aspectos terapêuticos. }\end{array}$ \\
\hline LIMA et al & 2017 & $\begin{array}{l}\text { A transmissão de orientações sobre medicamentos ê } \\
\text { fundamental para a adesão ao tratamento e êxito da } \\
\text { terapia farmacológica. }\end{array}$ \\
\hline LIMA, BENJAMIN e SANTOS & 2017 & $\begin{array}{l}\text { A importância do profissional farmacêutico nesse } \\
\text { contexto é enfatizada no ato de dispensar e passar as } \\
\text { devidas informações acerca do modo adequado de se } \\
\text { usar o medicamento; O farmacêutico também possui } \\
\text { a responsabilidade de averiguar a veracidade das } \\
\text { receitas e reforçar a orientação quanto ao uso racional } \\
\text { do antibiótico. }\end{array}$ \\
\hline
\end{tabular}

Fonte: Os autores

A utilização de antimicrobianos no cenário atual ocorre entre as diferentes classes e faixas etárias. Estima-se que mais de 50\% das prescrições de antimicrobianos são consideradas inapropriadas e que os consumidores fazem o uso do medicamento fora do tempo recomendado, além de que dois terços se utilizam do medicamento sem prescrição e $90 \%$ o 
adquirem para um período estimado de três dias ${ }^{(9)}$. O resultado do uso desordenado desta classe medicamentosa acarreta no aparecimento de cepas de micro-organismos resistentes o que leva ao agravamento do caso clínico do paciente, dificultando assim o controle da doença ${ }^{(10)}$.

Com base em um levantamento feito pelo Instituto de Ciência e Tecnologia e Qualidade (ICTQ) 76,4\% da população brasileira se automedica. A automedicação é definida como uma prática muito simples e comum entre a população, sendo considerada atualmente um dos principais problemas de saúde pública no Brasil e no mundo. Foi possível traçar um perfil epidemiológico de estudantes que praticavam a automedicação, dentre as causas desta prática $76,55 \%$ dos entrevistados que cursavam a área da saúde e 76,61\% dos demais cursos apontaram familiares/amigos como principal orientação para o uso de antibióticos, o que se assemelha com os resultados obtidos na pesquisa, estes dados se tornam alarmante quando se pensa nas consequências deste ato ${ }^{(11)}$.

Foi possível observar com base nos resultados encontrados no estudo alguns fatores que motivaram a utilização de antimicrobianos sem a orientação de um profissional capacitado, dentre eles deve-se destacar: Problema de saúde simples seguido de algum conhecimento prévio da patologia, uso de prescrições antigas, influência de amigos e/ou familiares e dificuldade de acesso aos serviços de saúde. Aponta-se que 54\% dos entrevistados justificaram se automedicar movido pela experiência anterior com o medicamento utilizado e 48,7\% acharam que por apresentarem sintomas muito simples, não consideraram necessária a ida ao médico $^{(12)}$.

Com base em dados, uma das formulações mais consumidas em comunidades ribeirinhas da Amazônia foi a amoxicilina tri-hidratada que pertence ao grupo dos antibióticos, e dentre os fatores que levaram ao uso do medicamento os mesmos apontaram a experiência prévia por prescrições antigas como determinante para automedicação. Sendo utilizadas com os sinais de dor, gripe, problemas gastrointestinais e outros ${ }^{(13)}$. As comunidades ribeirinhas sofrem com a falta de serviços de saúde de qualidade para a continuidade do tratamento de patologias, o que incentiva a prática do estoque de fármacos ${ }^{(14)}$.

Conforme identificado em estudos publicados, existem várias razões pelas quais as pessoas se automedicam das mais diversificadas. A propaganda desenfreada e massiva de determinados medicamentos é uma delas, quando se contrasta com as tímidas campanhas que tentam esclarecer os perigos da automedicação. A automedicação é fortemente influenciada 
por propaganda e publicidade tendenciosas, que como consequência podem ocasionar sérios problemas como intoxicações e até mesmo ser letal ${ }^{(15)}$.

Mediante a isto, e mesmo com o surgimento e desenvolvimento de fármacos que combatem infecções bacterianas acarretarem uma melhora significativa no combate as infecções, o aumento da automedicação levou ao aparecimento de micro-organismos resistentes, sendo estes considerados um grande risco para a população por diminuírem as opções de fármacos efetivos utilizados na farmacoterapia ${ }^{(16)}$. Com base no cenário atual e na análise dos dados, os autores apontaram grande preocupação quanto às consequências voltadas para o uso irracional de antimicrobianos, destacando-se a resistência bacteriana como um problema de saúde pública.

Em uma das bibliografias para formulação desse artigo, o qual tinha um dos objetivos determinar o perfil de resistência frente aos antimicrobianos, identificou-se que o hospital alvo possuiu cepas resistentes e peculiaridades no perfil de resistência dos microrganismos ali encontrados. O mesmo ainda enfatizou a importância da necessidade de mais estudos com essa temática para um maior controle das taxas de resistência, visando à utilização desses dados como ferramenta norteadora dos médicos na escolha de uma melhor farmacoterapia ${ }^{(17)}$.

Além deste agravante, os resultados mostraram outros pontos preocupantes quando se trata de automedicação, como por exemplo, o aparecimento de reações adversas e a toxicidade, que são reações que variam de leves até a casos graves que podem vir a ocorrer quando se faz uso de qualquer tipo de medicamento sem orientação de algum profissional da saúde ${ }^{(18)}$. Também como consequência o elevado custo final devido ao aumento do tempo de internação e consumo de medicamentos, o que corrobora com a ideia de que o aumento da resistência bacteriana a vários agentes leva a maiores cuidados no manejo de infecções e favorece o aumento dos custos do sistema de saúde ${ }^{(19)}$.

Devido a este cenário, deve-se destacar a importância do farmacêutico que a partir da sua formação possui uma visão ampla da realidade da saúde. Ele é o profissional mais habilitado a fornecer informações, pois é conhecedor das doenças mais prevalentes, entende dos medicamentos que as curam, sabe sobre a terapêutica medicamentosa e deve estar facilmente disponível nos estabelecimentos ${ }^{(20)}$.

Com base na análise dos resultados obtidos, se destaca a importância da intervenção do profissional farmacêutico no ato da dispensação ${ }^{(21)}$. Esse momento é crucial de interação entre o farmacêutico e o paciente, pois a partir desse diálogo são repassadas as devidas informações 
sobre o modo adequado de se utilizar o medicamento. Este achado corrobora com as ideias que apontou os objetivos da intervenção farmacêutica que são: identificar, corrigir ou reduzir possíveis erros associados a terapêutica além de promover as condições para que o paciente use do medicamento da melhor maneira possível ${ }^{(22)}$.

Nesse contexto, vale ressaltar que o farmacêutico deve ser responsável por repassar as orientações adequadas para o paciente, esclarecer dúvidas e orientar a forma correta de administração do medicamento ${ }^{(23)}$. Seguindo esse mesmo fundamento destaca-se o papel do farmacêutico no que diz respeito ao uso de antibióticos, enfatizando a responsabilidade do mesmo em repassar informações adequadas sobre o medicamento prescrito por meio do diálogo com o paciente, pois essa classe medicamentosa exige uma maior atenção quanto ao período de utilização por estar relacionado ao aumento da resistência bacteriana ${ }^{(24)}$.

Diante do exposto é notório o quanto se faz necessário as devidas informações e intervenções na utilização do medicamento. Com o estudo realizado em um Hospital Oncológico no Sul do Brasil com prescrições, foi possível observar a identificação de problemas relacionados a medicamentos e a prevenção da maioria deles a partir da intervenção farmacêutica $^{(25)}$. O artigo corrobora com os estudos que demonstraram uma diminuição significativa de erros de medicação e redução de eventos adversos em instituições que possuíam o farmacêutico intervindo na equipe clínica, resultando assim na qualidade assistencial e diminuição de custo hospitalares ${ }^{(26)}$.

\section{CONCLUSÃO}

Nesse estudo foi possível identificar a partir da análise na literatura um número relevante de fatores que levam a automedicação de antimicrobianos com destaque para praticidade, alívio rápido de sintomas, uso de prescrição antiga e dificuldade de acesso à serviço de saúde. Diante desses agravantes foi possível evidenciar também, a principal consequência do uso indevido desta classe que são os aumentos dos casos de resistência bacteriana que atualmente vem se tornando um problema de saúde pública. Contudo torna-se evidente a importância da intervenção farmacêutica no ato da dispensação e na realização de atividades de educação em saúde, que possui caráter educativo e corretivo, visando a assim a prevenção através das orientações garantido ao usuário informações quanto ao uso racional de medicamentos. 


\section{REFERÊNCIAS BIBLIOGÁFICAS}

1. Franco JMPL, Mendes RC, Cabral FRF, Menezes CDA. O papel do farmacêutico frente à resistência bacteriana ocasionada pelo uso irracional de antimicrobianos. Rev Cient Semana Acadêmica. 2015; 1(72):1-17. ISSN 2236-6717.

2. Saldanha DMS, Souza MBM, Ribeiro JF. O uso indiscriminado dos antibióticos: uma abordagem narrativa da literatura. Rev Interfaces da Saúde. 2018;(8):12-37. ISSN 2358-517x.

3. Vieira PN, Vieira SLV. Uso irracional e resistência a antimicrobianos em hospitais. Arq Cienc Saúde. 2017;21(3): 209-212. ISSN 1982-114X. DOI: https://doi.org/10.25110/arqsaude.v21i3.2017.6130.

4. Silva JO, Paixão JA. Resistência bacteriana e a atuação do farmacêutico na promoção do uso racional de antibacterianos em âmbito hospitalar. Rev Artigos.Com. 2021;29:e7563. ISSN 2596-0253.

5. Soterio KA, Santos MA. A automedicação no Brasil e a importância do farmacêutico na orientação do uso racional de medicamentos de venda livre: uma revisão. Rev Gradu. 2016;9(2).

6. Teixeira AR, Figueiredo AFC, França RF. Resistência bacteriana relacionada ao uso indiscriminado de antibióticos. Rev Saúde em Foco. 2019;(11):853-875.

7. Sampaio PS, Sancho LG, Lago RF. Implementação da nova regulamentação para prescrição e dispensação de antimicrobianos: possibilidades e desafios. Cadernos Saúde Coletiva. 2018;26(1):15-22. v. 26, p. 15-22, 2018. ISSN 2358-291X. DOI: https://doi.org/10.1590/1414$462 \times 201800010185$.

8. Gonçalves JR. Como escrever um Artigo de Revisão de Literatura. Rev JRG Estudos Acadêmicos. 2019;2(5):29-55. ISSN 2595-1661. DOI: https://doi.org/10.5281/zenodo.4319105.

9. Piltcher OB, Kosugi EM, Sakano E, Mion O, Testa JRG, Romano FR, Santos MCJ, Francesco RCC, Mitre EI, Bezerra TFP, Roithmann R, Padua FG, Valera FCP, Lubianca Neto JF, Sá LCB, Pignatari SSN, Avelino MAG, Caixeta JAS, Anselmo-Lima WT, Tamashiro E. Como evitar o uso inadequado de antibióticos nas infecções de vias aéreas superiores? Posição de um painel de especialistas. Brazi Jour of Otorhino. 2018;84(3):265-279. DOI: https://doi.org/10.1016/j.bjorl.2018.02.001.

10. Gama AS, Secoli SR. Automedicação em estudantes de enfermagem do Estado do Amazonas - Brasil. Rev Gaúcha Enferm. 2017;38(1):e65111. DOI: http://dx.doi.org/10.1590/1983-1447.2017.01.65111.

11. Campos L, Teixeira BC, Casalini CEC. Perfil da automedicação em estudantes de ensino superior: impacto na resistência bacteriana. Rev saúde integrada. 2019;12(24):67-78. ISSN 2447-7079. 
12. Matos JF, Pena DAC, Parreira MP, Santos TC, Coura-Vita W. Prevalência, perfil e fatores associados à automedicação em adolescentes e servidores de uma escola pública profissionalizante. Cad. Saúde Colet. 2018;26(1):76-83. ISSN 2358-291X. DOI: https://doi.org/10.1590/1414-462X201800010351.

13. Gama ASM, Secoli SR. Práticas de automedicação em comunidades ribeirinhas na Amazônia brasileira. Rev Bras Enferm. 2020;73(5):e20190432. DOI: http://dx.doi.org/10.1590/0034-7167-2019-0432.

14. Guimarães AF, Barbosa VLM, Silva MP, Portugal JKA, Reis MHS, Gama ASM. Acesso a serviços de saúde por ribeirinhos de um município no interior do estado do Amazonas, Brasil. Rev Pan Amaz Saude 2020;11:e202000178. ISSN: 2176-6223. DOI: 10.5123/S21766223202000178 .

15. Paim RSP, Lunelli RP, Zanchett K, Menon P, Costa S, Gianchelin T. Automedicação: uma síntese das publicações nacionais. Rev Contexto \& Saúde. 2016;16(30):47-54.

16. Costa AL, Silva Júnior A. Resistência bacterina aos antibióticos e Saúde Pública: uma breve revisão de literatura. Estação Científica. 2017;7(2):45-57. ISSN 2179-1902. DOI: http://dx.doi.org/10.18468/estcien.2017v7n2.p45-57.

17. Dantas LS, Santos AG. Microrganismos Mais Frequentes e Antimicrobianos Utilizados em Pacientes Internados em Unidades de Terapia Intensiva. Rev rede cuid saud. 2016;10(3):1-15. ISSN 1982-6451.

18. Chagas GFF, Luna GG, Izel ICM, Orientadora ACGA. O impacto da prática da automedicação no Brasil: Revisão Sistemática. Brazilian Applied Science Review. 2021;5(3):1505-1518. ISNN 2595-3621. DOI:10.34115/basrv5n3-016.

19. Furtado DMF, Silveira VS, Carneiro ICRS, Furtado DMF, Kilishek MP. Consumo de antimicrobianos e o impacto na resistência bacteriana em um hospital público do estado do Pará, Brasil, de 2012 a 2016. Rev Pan Amaz Saude 2019;10:e201900041. ISSN: 2176-6223. DOI: $10.5123 / \mathrm{S} 2176-6223201900041$.

20. Bonfim G. A Importância do Profissional de Farmácia na Atenção Farmacêutica. Rev Cient Multi. 2020;1(2):1-11. DOI: https://doi.org/10.51473/rcmos.v1i1.3

21. Moreira LR, Matsunaga PAS, Galete J, Moreira RS, Lima LYR, Barbosa SRM, Penha RM, Polisel CG. Erros de dispensação de medicamentos e intervenções farmacêuticas relacionadas. Braz. J. of Develop. 2020;6(12):100887-100900, 2020. DOI: 10.34117/bjdv6n12-543.

22. Ribeiro EMS, Arroyo-Rodríguez V, Santos BA, Tabarelli M, Leal IR. Chronic anthropogenic disturbance drives the biological Impoverishment of the Brazilian Caatinga vegetation. Dryad Digital Repository. 2015;52(3):611-620. DOI: http://dx.doi.org/10.5061/dryad.m7d8m.

23. Lima CC, Benjamin SC, Santos RF. Mecanismo de resistência bacteriana frente aos fármacos: Uma revisão. CuidArte, Enferm. 2017;11(1):105-113. 
24. Souza RP, Rosa PRG, Souza IF, Maikot SCV, Custódio GR. A atenção farmacêutica no uso racional de antibióticos: uma revisão narrativa. Rev Art.Com. 2021;26:e6112. ISSN 2596-0253.

25. Aguiar KS, Santos JM, Cambrussi MC, Picolotto S, Carneiro MB. Patient safety and the value of pharmaceutical intervention in a cancer hospital. Einstein. 2018;16(1):1-7. ISSN 16794508. DOI: 10.1590/S1679-45082018AO4122.

26. Sousa CJP, Prete ACL, Gomes AGP, Castro EFR, Ribeiro CHMA. Adverse drug events in hospitalized patients in Brazil: Integrative literature review. Research, Society and Development. 2021;10(4): e3410413818. ISSN 2525-3409. DOI: http://dx.doi.org/10.33448/rsd-v10i4.13818. 